\title{
The relation between birth weight and hypertension. A study among Danish nurses
}

\author{
Rie Adser Virkus ${ }^{1}$, Berit Heitmann $^{2}$, Erik Obel $^{3}$, Thomas Bergholt ${ }^{1}$, Ellen Løkkegaard ${ }^{1 \#}$ \\ ${ }^{1}$ Department of Obstetric and Gynecology, Hillerød Hospital, University of Copenhagen, Hillerød, Denmark; \\ \#Corresponding Author: ELOE0002@regionh.dk \\ ${ }^{2}$ Research Unit for Dietary Studies at Institute of Preventive Medicine, Bispebjerg and Frederiksberg Hospitals, Copenhagen Univer- \\ sity Hospital, Copenhagen, Denmark \\ ${ }^{3}$ The Danish Nurse Cohort Study, Glostrup, Denmark
}

Received 23 February 2013; revised 26 March 2013; accepted 5 April 2013

Copyright (C) 2013 Rie Adser Virkus et al. This is an open access article distributed under the Creative Commons Attribution License, which permits unrestricted use, distribution, and reproduction in any medium, provided the original work is properly cited.

\section{ABSTRACT}

The fetal origin hypothesis suggests that birth weight is related to several adult diseases. One hypothesis is that low birth weight is associated with increased risk of hypertension. In the present study we analyzed the association between self-reported birth weight and risk of hypertension with detailed confounder control, and the modification on this association by familial obesity and own weight history during childhood and youth. Methods: In 1999 the Danish Nurse Cohort study included 31,642 females aged 44 years or more of whom $76 \%$ replied to questions on birth weight, weight history, familial obesity disposition, parents socioeconomic status and presence of hypertension. Results: In total $14 \%$ reported birth weights below $3000 \mathrm{~g}$. The univariate hazard ratio of hypertension for those born with birth weight < $3000 \mathrm{~g}$ was $1.24(95 \% \mathrm{Cl}$ (1.13 - 1.36)) compared to those with birth weight $>3000 \mathrm{~g}$. The association remained stable after adjustment for important confounders, as lifestyle, weight history and socioeconomic status during upbringing. Conclusion: Our results support the hypothesis that low birth weight is associated with hypertension in adult life, also after considering several confounding factors and weight history later in life. Furthermore, the previous weight history might have an influence on the association between birth weight and the risk for adult hypertension.

\section{Keywords: Birth Weight; Hypertension; Weight}

*Conflict of interest: all authors declare: no support from any organization for the submitted work.
History

\section{INTRODUCTION}

The association between birth weight and risk of hypertension has been investigated in many previous studies [1-15] and the result suggesting an inverse association, has been remarkable robust. Barker extended his hypothesis with the "thrifty phenotype-hypothesis" that further suggested a connection between birth weight, hypertension and weight history later in life $[1,5,8,16$ 18]. The hypothesis suggested that an adaption to undernutrition in fetal life possibly changes the organism permanently with metabolic and endocrine consequences. It is supposed to be an epigenetic process involving the fetal renin-angiotensin system. These changes should be beneficial if nutrition remains scarce in childhood. But if nutrition in childhood becomes plentiful, however, these changes predispose to several chronic diseases, among other hypertension $[1,8,16,18]$. Despite the consistency of results on the association between birth weight and hypertension, a large pooling analysis based on 55 studies still questioned the relation and suggested that the inverse association was cased by random error, selective emphasis of particular results and inappropriate adjustment for current weight and for confounding factors, that would had led to an overestimation of the association between birth weight and adult hypertension [2]. Responds to that critical view accentuated that the effect of birth weight is conditioned by events occurring later in life, like weight history $[18,19]$. Furthermore, Tu et al. had questioned the use of current weight as a confounder, but suggested it as a covariate and additionally claimed that the evidence for the association between birth weight and hypertension is a statistical artifact [4].

On this background, the purpose of the present study 
was to examine associations between birth weight and adult hypertension, while considering the weight history between birth and adulthood, the familial predisposition to obesity and several important covariates known to influence the association between birth weight and hypertension in adulthood.

\section{MATERIAL AND METHODS}

\subsection{Population}

This study was based on data from the Danish Nurse Cohort study. In 1993, 23,190 female Danish nurses, all members of the Danish Nurse association and above the age of 44 years, received a comprehensive questionnaire concerning reproduction lifestyle and health, and 19,898 (86\%) answered. In 1999, 31,642 nurses were investigated. This group included nurses also invited in 1993, and in addition nurses who between 1993 and 1999 turned 45 years of age. In total 24,155 (76\%) answered the 1999 questionnaire of whom 20,791 had information of birth weight and hypertension. In total 15,322 nurses answered both the 1993 and 1999 questionnaire.

\subsection{Cases and Exposure}

Cases with hypertension were identified from the 1999 questionnaire by self-reported confirmation on having hypertension and the year it was diagnosed was considered the time of event. Participants with missing information on presence or absence of hypertension were excluded.

To be able to identify the incident hypertension cases during 1993-1999; those with full information, in both the 1993 and 1999, on hypertension and in 1999 on birth weight were extracted $(\mathrm{n}=12,089), 2730$ (17.8\%) had missing information on birth weight and 721 (4.7\%) missed information on hypertension.

Birth weight was recorded either with exact information of grams at birth or with information on category and birth weight, i.e. $<3 \mathrm{~kg}, 3-4.5 \mathrm{~kg},>4.5 \mathrm{~kg}$. In total 4199 participants gave their exact birth weights and 7890 participants filled in the weight category of their birth weight.

In total 2812 of the 1999 participants and 2187 of these participants in both 1993 and 1999 reported hypertension. Of them, 1043 were diagnosed in the period between 1993 and 1999.

\subsection{Confounders}

Information on confounders was obtained from the 1993 questionnaire. They comprise age, information on smoking (no, past, current 1 - 15 cigarettes/day, current $>15$ cigarettes/day), alcohol consumption (0, 1 - 14, 14 $21,>21$ units/week), leisure time physical activity (heavy
$>4$ hours/week, moderate $>4$ hours/week, inactive $<4$ hours/week), body mass index (BMI) (<18.5, 18.5 - 25, $25-30 \mathrm{~kg} / \mathrm{m}^{2}$ ) and a detailed variable on mothers and fathers education and relation to the labor marked (3 classes of salaried staff, skilled and unskilled worker, unemployed, under education, self-employed, indeterminable status, former, retirement pensioner, other pensioner, housewife, assisting spouse, dead) when the nurses were 18 years old.

Information on weight history was obtained from the 1999 questionnaire. It comprised three possible categories, i.e. were you heavier, slimmer or as most when you were a child (until 13 years), a teenager (from 13 to 19 years old) and as a young adult (from 19 to 25 years). Further, subjects were questioned about their weight and height at the age of 25 years. Also, pictograms were provided showing nine female and nine male figures of increasing size. Nurses were asked to select the figure that best represented the size of their mother and father at the age of around 40 years. A parent was considered overweight if nurses identified the top three figures as representing their size. A variable on familial predisposition to obesity was generated if one of the parents were pointed out as overweight in the pictogram and own body mass at the age of 25 years exceeded $25 \mathrm{~kg} / \mathrm{m}^{2}$.

\subsection{Statistical Analyses}

The distribution of background variables were assessed by chi-square tests. For calculation of risk associated with birth weight Cox proportional Hazard model were used. Age was used as underlying time for calculating hazard ratios for hypertension with low birth weight compared to normal or high birth weight. Time of event was defined as the self-reported year hypertension was diagnosed.

Distribution of birth weight according to hypertension, lifestyle and weight history was tabulated and chi-square test was calculated.

Cox proportional hazard models calculated univariate hazard ratios. Models were conducted with two endpoint definitions, considering all reported cases of hypertension since the participant was born or only the incident cases of hypertension in 1993-1999 as a subpopulation. Otherwise participants were censored at end of follow-up in 1999. Cox models of the two endpoint definitions of hypertension were fitted in two times nine multivariate models corrected for various confounding factors in 1993, i.e. lifestyle, parent's socio-economic status and weight history. Information on weight history comprises family obesity predisposition, child weight, teenage weight and young adult weight.

If there were no significant differences between the results with the two endpoint definitions, we found it acceptable to use the largest group, i.e. all cases until 1999. 
To test for effect modification of weight history, Cox models where fitted to analyze effect on birth weight on all cases of hypertension. The analyses were stratified according to the various variables on weight history. Interaction models between all measures of weight history and birth weight were fitted.

Additionally, the birth weight variable and the three weight history variables were combined and three sets of Cox models where fitted to calculate risk of hypertension with different levels of birth weight and weight history compared to normal birth with normal weight history.

Missing values were excluded from analysis. For every Cox model the proportional hazard assumption was checked graphically and with Schoenfield residuals. Analyses were performed in Stata Version 8.0.

\section{RESULTS}

Among nurses participating in 1993 and 1999, 1908 (15.8\%) reported a birth weight at or below $3000 \mathrm{~g}$.

Nurses with low birth weight were often slimmer as child-, teen- and young-adults and were less physically active, whereas no differences were seen in relation to consumption of alcohol, smoking habits or familial obesity disposition Table $\mathbf{1}$.

The results were not significantly different in the analyses based on results from all cases of hypertension until 1999 compared to those based on the incident cases of hypertension between 1993 and 1999. Therefore, we found it acceptable too base results on all reported cases until 1999.

Table 1. Lifestyle and weight history according to birth weight.

\begin{tabular}{|c|c|c|}
\hline \multirow{2}{*}{ Participants in 1993 and 1999} & \multicolumn{2}{|l|}{ Birth weight } \\
\hline & More than 3000 g, n = 10,181, n(\%) & Less than $3000 \mathrm{~g}, \mathrm{n}=1908, \mathrm{n}(\%)$ \\
\hline Hypertension (all 1999) & $1767(17.4)$ & $420(22.0)$ \\
\hline Incident cases (1993-1999) & $849(9.2)$ & $194(11.5)$ \\
\hline \multicolumn{3}{|l|}{ Physical activity, $\mathrm{p}<0.01$} \\
\hline Hard $>4$ hrs/wk & $2894(27.6)$ & $492(25.0)$ \\
\hline Light $>4$ hrs/wk & $7037(67.1)$ & $1347(68.3)$ \\
\hline Sedentary $<4$ hrs/wk & $560(5.3)$ & $134(6.8)$ \\
\hline \multicolumn{3}{|l|}{ Body mass index, $\mathrm{p}<0.01$} \\
\hline$<18.5 \mathrm{~kg} / \mathrm{m}^{2}$ & $222(2.1)$ & $62(3.1)$ \\
\hline $18.5-25 \mathrm{~kg} / \mathrm{m}^{2}$ & $7442(70.7)$ & $1402(70.4)$ \\
\hline $25-30 \mathrm{~kg} / \mathrm{m}^{2}$ & $2346(22.3)$ & $426(21.4)$ \\
\hline$>30 \mathrm{~kg} / \mathrm{m}^{2}$ & $516(4.9)$ & $103(5.2)$ \\
\hline \multicolumn{3}{|l|}{ Alcohol, $\mathrm{p}=0.10$} \\
\hline 0 units/wk & $1532(15.0)$ & 326 (16.8) \\
\hline 1 - 14 units/wk & $6373(62.6)$ & $1170(60.3)$ \\
\hline 14 - 21 units/wk & $1312(11.2)$ & $241(12.4)$ \\
\hline >21 units/wk & $970(9.5)$ & $202(10.4)$ \\
\hline \multicolumn{3}{|l|}{ Smoking, $\mathrm{p}=0.22$} \\
\hline No & $3521(35.1)$ & $665(34.7)$ \\
\hline Past & 2967 (29.6) & $535(28.0)$ \\
\hline Current 1 - 15 cigarettes & $1886(18.8)$ & 395 (20.6) \\
\hline Current $>15$ cigarettes & 1655 (16.5) & 319 (16.7) \\
\hline \multicolumn{3}{|l|}{ Familial obesity, $\mathrm{p}=0.5$} \\
\hline No & $9586(95.9)$ & 1779 (96.2) \\
\hline Yes & $410(4.1)$ & $70(3.8)$ \\
\hline \multicolumn{3}{|l|}{ Child weight, $\mathrm{p}<0.01$} \\
\hline As most & $7179(68.3)$ & $1139(57.6)$ \\
\hline Bigger than most & $1013(9.6)$ & $149(7.5)$ \\
\hline Slimmer than most & $2319(22.1)$ & $688(34.8)$ \\
\hline \multicolumn{3}{|l|}{ Teen weight, $\mathrm{p}<0.01$} \\
\hline As most & $7650(72.8)$ & $1356(68.6)$ \\
\hline Bigger than most & $1288(12.3)$ & $203(10.3)$ \\
\hline Slimmer than most & $1572(15.0)$ & 417 (21.1) \\
\hline \multicolumn{3}{|l|}{ Young weight, $\mathrm{p}<0.01$} \\
\hline As most & $8236(78.2)$ & $1438(72.5)$ \\
\hline Bigger than most & $630(6.0)$ & $115(5.8)$ \\
\hline Slimmer than most & $1670(15.9)$ & $430(21.7)$ \\
\hline \multicolumn{3}{|l|}{ BMI 25 years, $\mathrm{p}<0.01$} \\
\hline$<18.5 \mathrm{~kg} / \mathrm{m}^{2}$ & 707 (8.7) & $212(14.0)$ \\
\hline $18.5-25 \mathrm{~kg} / \mathrm{m}^{2}$ & $7080(86.6)$ & $1220(80.5)$ \\
\hline$>25 \mathrm{~kg} / \mathrm{m}^{2}$ & $385(4.7)$ & $83(5.5)$ \\
\hline
\end{tabular}

Abbreviations: hrs: hours; wk: week; BMI: body mass index. 
Compared to nurses who reported a normal or a high birth weight, a birth weight equal to or less than $3000 \mathrm{~g}$ was associated with a $25 \%$ higher risk of developing hypertension (Odds ratio $(\mathrm{OR})=1.24$ (95\% confidence intervals (CI) 1.13, 1.36)). The association remained stable after adjustment for various confounders Table 2.

\section{Effect Modification}

When stratifying the results according to familial obesity predisposition, the association between birth weight and risk for hypertension was significant only for the women without familial predisposition (OR = 1.27 (95\%
CI: 1.15, 1.41)). Looking only at women having a familial obesity predisposition, the risk was no longer significant $(\mathrm{OR}=0.99$ (95\% CI: 0.64, 1.52)).

Women's own weight history modified the associations in such a way, that the highest risk for attaining adult hypertension was seen for those who were born with low birth weight and became bigger than most later on, especially in the teenage- and young-adult years. However, also the women reporting a lower weight during growth had a higher risk of hypertension. The highest risk was found for those deviating from a normal weight history and born with low birth weight Table 3 .

Table 2. Risk of hypertension with birth weight at or below $3000 \mathrm{~g}$ compared to above $3000 \mathrm{~g}$, considering two hypertension definitions and various models and control for confounders at all cases of hypertension in 1999 and incident cases 1993-1999.

\begin{tabular}{|c|c|c|c|}
\hline \multicolumn{2}{|c|}{$\begin{array}{l}\text { Participants in } 1993 \text { and } 1999 \\
\text { All hypertension cases until } 1999\end{array}$} & \multicolumn{2}{|c|}{$\begin{array}{l}\text { Birth weight } \\
\text { Incident hypertension cases } 93 \text { - 99, } \\
\text { after information on confounding factors }\end{array}$} \\
\hline n of total & Odds ratio $(95 \% \mathrm{CI})$ & n of total & Odds ratio $(95 \% \mathrm{CI})$ \\
\hline $2812 / 20,791^{1}$ & $1.24(1.13,1.36)$ & $1435 / 20,791$ & $1.16(1.02,1.33)$ \\
\hline $2187 / 12,089^{2}$ & $1.26(1.14,1.40)$ & $1043 / 10,945$ & $1.20(1.03,1.41)$ \\
\hline $1989 / 11,002^{3}$ & $1.23(1.10,1.38)$ & $951 / 9964$ & $1.18(1.00,1.39)$ \\
\hline $1974 / 10,950^{4}$ & $1.26(1.13,1.41)$ & $944 / 9920$ & $1.21(1.03,1.43)$ \\
\hline $1948 / 10,808^{5}$ & $1.26(1.13,1.41)$ & 935/9795 & $1.21(1.03,1.43)$ \\
\hline $1946 / 10,792^{6}$ & $1.25(1.12,1.40)$ & $932 / 9778$ & $1.20(1.02,1.42)$ \\
\hline $1962 / 10,880^{7}$ & $1.24(1.10,1.39)$ & 938/9856 & $1.18(1.00,1.40)$ \\
\hline $1964 / 10,881^{8}$ & $1.26(1.11,1.39)$ & 939/9856 & $1.19(1.01,1.41)$ \\
\hline $1969 / 10,906^{9}$ & $1.25(1.12,1.40)$ & $940 / 9877$ & $1.20(1.01,1.41)$ \\
\hline $1491 / 8520^{10}$ & $1.25(1.09,1.42)$ & 730/8520 & $1.25(1.04,1.50)$ \\
\hline $1849 / 10,360^{11}$ & $1.27(1.13,1.42)$ & 886/9397 & $1.22(1.03,1.45)$ \\
\hline
\end{tabular}

${ }^{1}$ The 1999 population univariate; ${ }^{2}$ The population investigated both in 1993 and 1999 univariate; ${ }^{3}$ Adjusted for smoking, alcohol and physical activity; ${ }^{4}$ Adjusted for smoking, alcohol, physical activity and BMI; ${ }^{5}$ Adjusted for smoking, alcohol, physical activity and BMI and mother's work; ${ }^{6}$ Adjusted for smoking, alcohol, physical activity and BMI and father's work; ${ }^{7}$ Adjusted for smoking, alcohol, physical activity and BMI and child weight; ${ }^{8}$ Adjusted for smoking, alcohol, physical activity and BMI and teen weight; ${ }^{9}$ Adjusted for smoking, alcohol, physical activity and BMI and young adult weight; ${ }^{10}$ Adjusted for smoking, alcohol, physical activity and BMI at 25 years; ${ }^{11}$ Adjusted for smoking, alcohol, physical activity and genetic obesity disposition.

Table 3. Proportional hazard ratios with 95\% confidence intervals (CI) of hypertension at different levels of birth weight and weight history as child, teenager and young adult compared to normal birth weight with normal weight history, 1999 population.

\begin{tabular}{|c|c|c|c|}
\hline \multicolumn{4}{|c|}{ Hazard ratios (95\% CI) and numbers } \\
\hline Birth/Child weight & As most & Slimmer than most & Bigger than most \\
\hline$>3000 \mathrm{~g}$ & $\begin{array}{c}1 \text { (ref) } \\
n=11,541\end{array}$ & $\begin{array}{c}1.12(1.02,1.24) \\
n=3936\end{array}$ & $\begin{array}{c}1.33(1.16,1.51) \\
n=1840\end{array}$ \\
\hline Birth/Teen age weight & As most & Slimmer than most & Bigger than most \\
\hline$<3000 \mathrm{~g}$ & $\begin{array}{c}1.29(1.13,1.42) \\
n=2203\end{array}$ & $\begin{array}{c}1.39(1.13,1.65) \\
n=776\end{array}$ & $\begin{array}{c}1.50(1.16,1.94) \\
n=365\end{array}$ \\
\hline$>3000 \mathrm{~g}$ & $\begin{array}{c}1 \text { (ref) } \\
n=12,257\end{array}$ & $\begin{array}{c}1.20(1.13,1.42) \\
n=2860\end{array}$ & $\begin{array}{c}1.20(1.06,1.36) \\
n=2189\end{array}$ \\
\hline$<3000 \mathrm{~g}$ & $\begin{array}{c}1.31(1.17,1.46) \\
n=2349\end{array}$ & $\begin{array}{c}1.27(1.05,1.55) \\
n=779\end{array}$ & $\begin{array}{c}1.77(1.28,2.36) \\
n=222\end{array}$ \\
\hline$>3000 \mathrm{~g}$ & $\begin{array}{c}1 \text { (ref) } \\
n=13,182\end{array}$ & $\begin{array}{c}1.17(1.05,1.31) \\
\mathrm{n}=2930\end{array}$ & $\begin{array}{c}1.61(1.40,1.87) \\
n=1223\end{array}$ \\
\hline
\end{tabular}




\section{DISCUSSION}

Our results are in support of previous findings that a low birth weight is associated with hypertension in adult life. This association, however, was seen only among those who did not have a familial predisposing to obesity. A deviation from a normal weight development during childhood and adolescence was furthermore associated with an increased risk of adult hypertension, independently of familial obesity and childhood socioeconomic condition. Indeed, we found an almost $25 \%$ higher risk for hypertension for those women who were born with a birth weight at or below $3000 \mathrm{~g}$, compared to those with a birth weight above $3000 \mathrm{~g}$, a result that remained remarkably stable after controlling for potential confounders. The inverse correlation between birth weight and hypertension remained stable when controlling for smoking, alcohol, physical activity and mothers and fathers work. This finding is in accordance with other studies [3, $8,10,14,17,20,21]$.

\subsection{Genetic Factors}

When stratifying according to whether nurses had parents with overweight, we found that a low birth weight was related to hypertension among the women with normal weight parents only, suggesting that a low birth weight did not influence adult hypertension among those prone to obesity, because of their familial obesity predisposition. It has been shown, that those women with familial predisposition to obesity are more sensitive to dietary obesity and this general sensitivity to become obese may mask associations between birth weight and adult hypertension [22]. No former studies have investigated how genetic susceptibility to obesity may influence the association between birth weight and adult hypertension, but in a historical cohort study Poulter et al. aimed to exclude genetic factors in general by investigating 492 twins [12]. In this study monozygotic and dizygotic twins did show a similar association. They therefore excluded that confounding by genetic - or environmentalfactors were the main explanations for the inverse association between birth weight and blood pressure [12].

\subsection{Child, Teen and Adult Weight History}

We did find a tendency for a relation between low birth weight, the weight history later in life and the risk for hypertension. In general the risk for hypertension was increasing for those who were bigger than most-especially in the teenage- and young-adult weight. This increased risk was even more pronounced for those born with a low birth weight. Other studies support this $[1,5$, 11,23].

\subsection{Limitations}

We did not have data for gestational age. However, others have additionally adjusted for gestational age and found similar results with and without such adjustments even if stronger inverse associations were found for those born at term than those preterm. In this context it has been suggested, that the birth weight at term reflects underlying processes of fetal growth impairment more than the birth weight for those born preterm [14]. Potentially therefore, the fact that we could not adjust for gestational age, may have led to an underestimation of the true associations.

Another potential weakness is that we do not know how many were born as twins or triplets. These are more often born preterm and with a lower weight for gestational age. Again, this would have attenuated rather than accentuated our findings. All variables included (birth weight, hypertension and the different confounder variables) were self-reported. Assuming that such recall bias is random, this would also have led to an attenuation of our results. Furthermore, we believe the self-reported data in the present study indeed has high validity, as suggested by a previous study that validated the birth weight recordings from this cohort and found a sensitivity of $91.9 \%$ for normal birth weight (3000 - $4499 \mathrm{~g}$ ) and of $74 \%$ at low birth weight (under $3000 \mathrm{~g}$ ). The positive predictive values were $92.5 \%$ for normal birth weight, and $70.8 \%$ for low birth weight [24]. These findings are similar to those found in the American Nurse Cohort Study II [13].

The questionnaire comprised three rather subjective categories on weight during childhood and adolescence. Residual confounding is a possibility and cannot be excluded. However, previous studies did not adjust at all for weight fluctuations during childhood and adolescence, and hence, this is the first attempt to try and control for this.

As regards the self-reported hypertension diagnosis, we believe that nurses, who have easily access to health care, may be more likely to be diagnosed with hypertension, if affected, than people in general. They also technically know how to diagnose hypertension. It is therefore less likely that errors in reporting explain our results.

\subsection{Strengths}

Our cohort represents a homogeneous sample of women including more than 20,000 participants. We have made a detailed confounder control, both in relation to socioeconomic status at time of birth and to current lifestyle. Indeed our results still show a statistically strong inverse relation between birth weight and hypertension as adults. 


\subsection{Conclusion}

Our results support the hypothesis that low birth weight is associated with hypertension in adult life, also after considering confounding factors. A stronger association between birth weight and hypertension was found for women who did not follow a normal weight-pattern in childhood and adolescence, indicating that non-normal weight gain during childhood, adolescence and early adulthood increase the adulthood hypertension-risk, compared to those born with normal birth weight and normal growth pattern. Hence, the present study suggests that the previous weight history might influence the association between birth weight and hypertension later in life. Also, the association between birth weight and hypertension was observed among those with a familial predisposition to obesity only, suggesting that a high sensitivity towards obesity may mask or overrule potential associations between birth weight and adult hypertension, and that such associations therefore can be observed among individuals without predisposed to obesity, only.

\section{ACKNOWLEDGEMENTS}

This work was supported by the local research foundation at Hillerød Hospital; which had no role in the study planning, data collection, or analysis, or in the writing the article or in the decision to submit the article for publication. All authors are independent from funder.

\section{REFERENCES}

[1] Barker, D.J., Eriksson, J.G., Forsen, T. and Osmond, C. (2002) Fetal origins of adult disease: Strength of effects and biological basis. International Journal of Epidemiology, 31, 1235-1239. doi:10.1093/ije/31.6.1235

[2] Huxley, R., Neil, A. and Collins, R. (2002) Unravelling the fetal origins hypothesis: Is there really an inverse association between birthweight and subsequent blood pressure? Lancet, 360, 659-665. doi:10.1016/S0140-6736(02)09834-3

[3] Kramer, M.S. (2000) Invited commentary: Association between restricted fetal growth and adult chronic disease: Is it causal? Is it important? American Journal of Epidemiology, 152, 605-608. doi:10.1093/aje/152.7.605

[4] Tu, Y.K., West, R., Ellison, G.T. and Gilthorpe, M.S. (2005) Why evidence for the fetal origins of adult disease might be a statistical artifact: The "reversal paradox" for the relation between birth weight and blood pressure in later life. American Journal of Epidemiology, 161, 27-32. doi:10.1093/aje/kwi002

[5] Eriksson, J.G., Forsen, T.J., Kajantie, E., Osmond, C. and Barker, D.J. (2007) Childhood growth and hypertension in later life. Hypertension, 49, 1415-1421. doi:10.1161/HYPERTENSIONAHA.106.085597

[6] Forsdahl, A. (1977) Are poor living conditions in childhood and adolescence an important risk factor for arteriosclerotic heart disease? British Journal of Preventive \&
Social Medicine, 31, 91-95.

[7] Barker, D.J., Osmond, C., Golding, J., Kuh, D. and Wadsworth, M.E. (1989) Growth in utero, blood pressure in childhood and adult life, and mortality from cardiovascular disease. $B M J$, 298, 564-567. doi:10.1136/bmj.298.6673.564

[8] Barker, D.J., Osmond, C., Forsen, T.J., Kajantie, E. and Eriksson, J.G. (2007) Maternal and social origins of hypertension. Hypertension, 50, 565-571. doi:10.1161/HYPERTENSIONAHA.107.091512

[9] Davies, A.A., Smith, G.D., May, M.T. and Ben-Shlomo, Y. (2006) Association between birth weight and blood pressure is robust, amplifies with age, and may be underestimated. Hypertension, 48, 431-436. doi:10.1161/01.HYP.0000236551.00191.61

[10] Lawlor, D.A., Hubinette, A., Tynelius, P., Leon, D.A., Smith, G.D. and Rasmussen, F. (2007) Associations of gestational age and intrauterine growth with systolic blood pressure in a family-based study of 386,485 men in 331,089 families. Circulation, 115, 562-568. doi:10.1161/CIRCULATIONAHA.106.646661

[11] Huxley, R.R., Shiell, A.W. and Law, C.M. (2000) The role of size at birth and postnatal catch-up growth in determining systolic blood pressure: A systematic review of the literature. Journal of Hypertension, 18, 815-831. doi:10.1097/00004872-200018070-00002

[12] Poulter, N.R., Chang, C.L., MacGregor, A.J., Snieder, H. and Spector, T.D. (1999) Association between birth weight and adult blood pressure in twins: Historical cohort study. BMJ, 319, 1330-1333. doi:10.1136/bmj.319.7221.1330

[13] Curhan, G.C., Chertow, G.M., Willett, W.C., Spiegelman, D., Colditz, G.A., Manson, J.E., et al. (1996) Birth weight and adult hypertension and obesity in women. Circulation, 94, 1310-1315. doi:10.1161/01.CIR.94.6.1310

[14] Leon, D.A., Koupilova, I., Lithell, H.O., Berglund, L., Mohsen, R., Vagero, D., et al. (1996) Failure to realise growth potential in utero and adult obesity in relation to blood pressure in 50 year old Swedish men. BMJ, 312, 401-406. doi:10.1136/bmj.312.7028.401

[15] Law, C.M., de Swiet, M., Osmond, C., Fayers, P.M., Barker, D.J., Cruddas, A.M., et al. (1993) Initiation of hypertension in utero and its amplification throughout life. BMJ, 306, 24-27. doi:10.1136/bmj.306.6869.24

[16] Robinson, S.M. and Barker, D.J. (2002) Coronary heart disease: A disorder of growth. Proceedings of the Nutrition Society, 61, 537-542. doi:10.1079/PNS2002189

[17] Hales, C.N. and Barker, D.J. (2001) The thrifty phenotype hypothesis. British Medical Bulletin, 60, 5-20. doi:10.1093/bmb/60.1.5

[18] Hales, C.N. and Barker, D.J. (1992) Type 2 (non-insulindependent) diabetes mellitus: The thrifty phenotype hypothesis. Diabetologia, 35, 595-601. doi:10.1007/BF00400248

[19] Eriksson, J.G. and Forsen, T. (2002) Unravelling the fetal origins hypothesis. Lancet, 360, 2072. doi:10.1016/S0140-6736(02)11951-9

[20] Barker, D.J. (2006) Birth weight and hypertension. Hypertension, 48, 357-358. 


\section{doi:10.1161/01.HYP.0000236552.04251.42}

[21] Leon, D.A., Johansson, M. and Rasmussen, F. (2000) Gestational age and growth rate of fetal mass are inversely associated with systolic blood pressure in young adults: An epidemiologic study of 165,136 Swedish men aged 18 years. American Journal of Epidemiology, 152, 597-604. doi:10.1093/aje/152.7.597

[22] Heitmann, B.L., Lissner, L., Sorensen, T.I. and Bengtsson, C. (1995) Dietary fat intake and weight gain in women genetically predisposed for obesity. American Journal of
Clinical Nutrition, 61, 1213-1217.

[23] Barker, D.J., Osmond, C., Kajantie, E. and Eriksson, J.G. (2009) Growth and chronic disease: Findings in the Helsinki Birth Cohort. Annals of Human Biology, 36, 445458. doi:10.1080/03014460902980295

[24] Wodskou, P.M., Hundrup, Y., Obel, E.B. and Jørgensen, T. (2010) Validity of self-reported birthweight among middle-aged and elderly women in the Danish nurses' cohort study. Acta Obstetricia et Gynecologica Scandinavica, 89, 1134-1139. doi:10.3109/00016349.2010.500370 